\title{
Announcement/Chronique
}

\section{Journal of Philosophical Research}

As of 1993 the Journal of Philosophical Research (formerly the Philosophy Research Archives) will be edited by Panayot Butchvarov, Professor of Philosophy at the University of Iowa and currently President of the APA's Central Division. He succeeds Robert Audi (University of Nebraska). No major policy changes are presently anticipated. The Journal will continue in its tradition of diversity of outlook and responsiveness to authors. Manuscripts prepared for blind review should be submitted, in triplicate and with four 150-word abstracts, to Ms. Cindy Richards at the Philosophy Documentation Center, with a check for $\$ 30.00$ made out to the PDC (half of this is refundable in case of rejection). Further details are printed in the Journal and in PDC publications; they are also obtainable by writing Ms.

Richards. 